\title{
ЭКОНОМИЧЕСКИЕ ФАКТОРЫ, ВЛИЯЮЩИЕ НА СТОИМОСТЬ СТРОИТЕЛЬСТВА
}

\section{(C) 2020 Мажанская Елизавета Владимировна}

бакалавр, студент магистратуры кафедры «Экспертиза и управление недвижимостью

Сибирский федеральный университет, Россия, Красноярск

E-mail: mazhanskaya97@mail.ru

(c) 2020 Пасечник Анастасия Сергеевна

студент специалитета кафедры «Строительство уникальных зданий и сооружений»

Сибирский федеральный университет, Россия, Красноярск

E-mail: pasechnicnastya14@mail.ru

(c) 2020 Калинина Дарья Александровна

студент специалитета кафедры «Строительство уникальных зданий и сооружений»

Сибирский федеральный университет, Россия, Красноярск

E-mail: daryakalinina2000@gmail.com

(c) 2020 Беккер Мария Станиславовна

студент специалитета кафедры «Строительство уникальных зданий и сооружений»

Сибирский федеральный университет, Россия, Красноярск

E-mail: mary.bekker.98@mail.ru

(c) 2020 Серебренникова Софья Андреевна

студент специалитета кафедры «Строительство уникальных зданий и сооружений»

Сибирский федеральный университет, Россия, Красноярск

E-mail: serebrennikova_s@list.ru

(C) 2020 Полегенько Анастасия Валерьевна

студент специалитета кафедры «Строительство уникальных зданий и сооружений»

Сибирский федеральный университет, Россия, Красноярск

E-mail: apolegenko@inbox.ru

В статье рассмотрены факторы влияющие на стоимость строительства, изучены элементы функционального процесса, обоснованы методы снижения затрат при строительстве, проанализирован вопрос о необходимости управления стоимостью строительства, а также исследованы тенденции в области аудита проектов строительства.

Ключевые слова: экономические факторы, стоимость строительства, методы снижения затрат, расчёт стоимости, индекс стоимости работ, смета расходов, стадии проектирования.

Экономические факторы оказывают существенное влияние на стоимость возведения объектов капитального строительства.

Так, управление стоимостью включает в себя детальное планирование затрат и контроль стоимости услуг для обеспечения участия строительных проектов в торгах, а также реализацию проекта в пределах заранее согласованной стоимости и наиболее экономичным образом в соответствии с программными требованиями и эстетическими соображениями [2].

Актуальность темы исследования обусловлена необходимостью обоснования экономиче- ских факторов, влияющих на стоимость строительства объектов.

При написании статьи были использованы труды отечественных авторов, это в частности: С.Ф. Валиев и М.Н. Ишемгулов, Н.А. Гаврилов, а также Е.А. Толмачев, В.А. Фисун и другие.

Все строительные проекты должны иметь независимый, объективный, профессиональный менеджмент стоимости в целях защиты финансовых интересов владельца.

Менеджер по стоимости (cost manager) использует свою подготовку и опыт с применением научных принципов и методов для анализа 
и разработки оптимального курса действий в отношении оценки, контроля затрат и рентабельности возводимого проекта. Используя принципы управления затратами, менеджер обеспечивает разработку проекта в рамках бюджета и является жизненно важным членом команды, который приносит дополнительную прибыль во время проектирования и строительства [5].

Навыки менеджера по стоимости базируются на опыте и знаниях в области расходов на строительство, что позволяет выполнять обязанности, сочетающие в себе функции экономиста, оценщика и бухгалтера и специально направлены на управление стоимостью строительства.

Опыт показывает, что инвесторы, которые включают менеджера по стоимости или сметчика в свою команду, от начала до завершения, как правило, получают максимальную отдачу от инвестиций в этот вид профессиональной деятельности.

В процессе развития проекта через различные стадии проектирования, менеджер (сметчик) подготовит элементарную смету расходов, которая будет использоваться для представления изменений и вариаций в предполагаемой стоимости, что позволяет своевременно принимать решения на добавления или удаления в проекте, сохраняя при этом начальный бюджет.

Во время проектирования и строительства вашего объекта, менеджер (сметчик) фактически становится одной из основных фигур команды проекта (Design Team), выступающей в качестве консультанта и технического менеджера и, в значительной мере, он будет определять финансовый успех проекта. Выбор менеджера (сметчика) не должен быть случайным процессом или проходить экспромтом, так как необходим специалист, чей опыт, интересы и возможности соответствуют лучшим требованиям, и с кем может хорошо работать вся проектная группа [1].

Существует множество факторов, которые влияют на расчёт стоимости строительства и оказывают существенное влияние на стоимость проекта и они таковы:

1. Аналогичные строительные проекты: для оценки работ, лучшей рекомендацией будут подобные проекты строительства. Конечная стоимость таких проектов может дать информацию для расчёта стоимости нового проекта строительства. Окончательная стоимость на основе проекта-аналога должна быть учтена в текущих индексах стоимости работ.

2. Стоимость строительных материалов: стоимость строительных материалов состоит из стоимости материалов, расходов на доставку и налогов, если таковые имеются. Важно учитывать все эти различия при расчёте стоимости строительного материала.

3. Ставки оплаты труда: заработная плата зависит от территории строительства. Так, следует принимать в расчёт местные ставки заработной платы. Если проект должен быть запущен после нескольких месяцев подготовки бюджета проекта, вероятные изменение ставок заработной платы необходимо учитывать в расчётах.

4. Условия строительства: условия строительного проекта могут увеличить затраты на строительство. Такие условия площадки, как плохие характеристики почвы, водно-болотных угодий, наличие загрязненных материалов, наличие инженерных сетей (закопанных труб, кабелей, воздушных линий), санитарно-защитные зоны, грунтовые воды, реки, транспортные коммуникации, археологические памятники, находящиеся под угрозой исчезновения виды животных и растений и места обитания, аналогичные существующим условиям могут увеличить стоимость проекта на этапе строительства, если эти изменения не учитываются при оценке.

5. Фактор инфляции: проект, строительство которого может продолжаться много лет до завершения. Во время строительства период, стоимость материалов, инструментов, работ и оборудования может меняться время от времени. Эти изменения в цене должны быть рассмотрены в процессе оценки стоимости.

6. График реализации проекта: длительность проекта строительства влияет на стоимость, в свою очередь увеличение длительности проекта может привести к увеличению стоимости строительства проекта за счет увеличения косвенных расходов, а снижение стоимости строительства также увеличивает стоимость проекта за счёт увеличения прямых затрат. Поэтому, при оценке стоимости проекта необходимо учитывать графики производства работ [4].

7. Качество проектной документации и спецификаций: хорошее качество чертежей и спецификаций снижает время работ по надлежащему исполнению на площадке. Любые расплывчатые формулировки или плохо разработанный проект не только вызывает недоумение, 
но ставит под сомнение труд исполнителя, что обычно приводит к удорожанию строительства.

8. Репутация инженерно-технического состава: плавный ход строительства жизненно важен для своевременного завершения проекта. Стоимость проекта будет выше при участии сотрудников, имеющих хорошую строительную профессиональную репутацию.

9. Нормативные требования: согласования регулирующих органов иногда могут быть дорогостоящим. Эти расходы также необходимо учитывать при оценке стоимости.

10. Требования к страхованию: оценка стоимости объектов строительства должна также учитывать стоимость страхования для различных инструментов, оборудования, строительных рабочих. В некоторых сложных проектах могут возникнуть дополнительные требования, которые повлекут дополнительные затраты.

11. Размер и тип строительства: при реализации масштабного строительного проекта может возникнуть высокий спрос на квалифицированную рабочую силу. Местные трудовые ресурсы могут быть недостаточными, что может повлечь дополнительные расходы на проекты, а также на тип строительства, где требуется специализированная рабочая сила.

12. Место строительства: когда площадка строительства находится далеко от имеющихся ресурсов, это увеличивает стоимость проекта. Стоимость перевозки рабочих, оборудования, материалов и инструментов увеличивается с расстоянием и добавляется к стоимости проекта.

13. Экспертиза: необходимо провести экспертизу проектной документации, которая прибавляется к стоимости проекта.

14. Резервы: всегда следует прибавить до 10\% непредвиденных расходов по отношению к общей стоимости проекта для непредвиденных расходов и инфляции.

Таким образом, необходимо отметить, что существуют различные эффективные методы для управления стоимостью строительства, многие из которых являются также энергосберегающими и легко оптимизируются. При реализации проекта возникает необходимость использования прочных, долговечных, экологически чистых, энергоэффективных и экономически выгодных материалов и соответствующих технологий в строительстве.

Снижение себестоимости может быть достигнуто одним из следующих способов:
- стоимостной инжиниринг;

- управление материальными ресурсами;

- бюджетный контроль;

- оптимизация затрат;

- снижение себестоимости на строительной площадке.

Необходимо использовать все приёмы снижения затрат, стоимости и повышения экономичности посредством использования альтернативных концепций дизайна, материалов и методов строительства без ущерба функциональным требованиям и качеству. Экономически эффективные методы строительства, материалов и различные стратегии управления в ходе выполнения проекта играют важную роль в экономии времени, а также снижают стоимость строительства [3].

При проведении технико-экономической оценки и выявлении эффективности проектов зданий, в которых предусмотрено поэтапное развитие в периодах эксплуатации, необходимо, наряду с использованием вышеприведенных факторов, учитывать следующее:

- изменение численности населения в районе расположения предприятия на выделенном временном интервале (горизонт планирования), а также информации о характере осуществляемого строительства предприятия в новом жилом районе;

- технико-экономические показатели для проведения комплексной оценки по каждому году горизонта планирования;

- базовые технико-экономические показатели, полученные в результате математической обработки показателей, характеризующие множество проектных решений;

- размер сэкономленной территории в результате осуществления поэтапного строительства.

Для выявления сроков и объёмов поэтапного ввода предприятия целесообразно использовать экономико-математическую модель (основное - горизонт планирования) на основе разработанных принципов и критериев техникоэкономической оценки.

Информацию о демографических изменениях в районе предполагаемого строительства объекта можно получить при анализе схем генерального развития района, а также планов детальной планировки района.

В практике современного градостроительства выделяют: 
- параллельное;

- последовательное;

- параллельно-последовательное направления ведения застройки.

Для параллельного ведения строительства характерна дробность захваток по всей территории, а также то, что окончание строительства одной структурной единицы (захватки) совпадает со сроком окончания строительства.

В заключение следует отметить, что стоимость строительства даже одинаковых объектов, построенных по одному типовому проекту не только в разных районах страны, но и на разных площадках в одном районе неодинакова и зави- сит от различных факторов.

Для упрощения расчёта затрат на строительство предприятий Госстроем РФ и другими ведомствами разработаны сметные нормативы, которые объединены и входят в IV часть СНиП. Вместе с положениями и правилами выполнения отдельных расчётов сметные нормативы служат исходной основой для нахождения сметной стоимости строительства новых предприятий, расширения, реконструкции и технического перевооружения действующих предприятий во всех отраслях народного хозяйства и промышленности.

\section{Библиографический список}

1. Валиев С. Ф., Ищемгулов М.Н. Факторы, влияющие на себестоимость жилищного строительства (на примере города Уфы) - «Молодой ученый» - № 2, 2017, стр.375-377;

2. Гаврилов Н. А. Анализ факторов, влияющих на стоимость жилой недвижимости - «Вологдинские чтения»№ 7, 2016, стр.42-43;

3. Толмачев Е.А., Монахов Б.Е. Экономика строительства - М., 2013, стр.224;

4. Фисун В.А. Экономика строительства - М., 2012, стр.232;

5. Шундулиди А.Б., Нагибина Н.В. Экономика отрасли (строительства) - Кемерово, 2016, стр.119. 